\title{
Extra-Nuclear Genetics
}

National Cancer Institute

\section{Source}

National Cancer Institute. Extra-Nuclear Genetics. NCI Thesaurus. Code C18786.

The genetics of extra-nuclear DNA, eg. Mitochondria and chloroplasts. 